\title{
Avaliação das propriedades físico-químicas de nanocompósitos de polietileno linear de baixa densidade e montmorilonita organofílica obtidos por extrusão
}

\author{
Evaluation of the physicochemical properties of low \\ linear density polyethylene and organophilic \\ montmorillonite nanocomposites \\ obtained by extrusion
}

\footnotetext{
${ }^{1}$ Mestrado em Engenharia de Processos, Universidade da Região de Joinville - UNIVILLE, Joinville - SC, e-mail:anapezzin@yahoo.com.br

${ }^{2}$ Departamento de Química, Universidade do Estado de Santa Catarina - UDESC, Joinville - SC

${ }^{3}$ Departamento de Engenharia de Materiais, Centro Universitário Sociesc - UNISOCIESC, Joinville - SC

${ }^{4}$ Laboratório de Soluções em Relaxometria, Instituto de Macromoléculas, Universidade Federal do Rio de Janeiro UFRJ, Rio de Janeiro - RJ
}

\begin{abstract}
RESUMO
Nanocompósitos de polietileno linear de baixa densidade com argila montmorilonita organofílica (OMMT) de fonte brasileira foram obtidos com o objetivo de avaliar as propriedades físico-químicas. Foram produzidos e caracterizados nanocompósitos obtidos por extrusão nas concentrações 2, 2,5, 3, 3,5\% e o polímero puro. As misturas foram injetadas e caracterizadas. As análises de TGA mostraram que a adição de nanoargila elevou a estabilidade térmica das amostras, principalmente a PELBD/OMMT2,0, cujo aumento foi de 5,6\% comparado ao Branco. O DSC demonstrou que a incorporação não influenciou na temperatura de fusão com relação a amostra pura do PELBD, entretanto, aumentou o grau de cristalinidade das amostras, destacando-se a amostra PELBD/OMMT2,5 que apresentou grau de cristalinidade 9,48\% maior que o branco. Os resultados de flamabilidade mostraram que a amostra PELBD/OMMT2,0 apresentou diminuição de $38 \%$ na velocidade de propagação de chama. No ensaio de tração, percebeu-se um aumento na rigidez das amostras com adição de OMMT, aumentando o módulo de Young e diminuindo o alongamento na ruptura com o aumento percentual de OMMT. Já a técnica de RMN mostrou que as amostras de até $2,5 \%$ de OMMT sugere a formação de um nanocompósito esfoliado, resultados comprovados por MEV/FEG, na qual amostras injetadas com uma quantidade superior a 2,5\% de argila apresentaram as mesmas características de delaminação.
\end{abstract}

Palavras-chave: Polietileno, Montmorilonita Organofílica, Nanocompósito.

\begin{abstract}
Low density linear polyethylene nanocomposites with organophilic montmorillonite clay (OMMT) from Brazilian source were obtained with the objective of evaluating the physicochemical properties. Nanocomposites obtained by extrusion at the concentrations $2,2.5,3,3.5 \%$ and the pure polymer were produced and characterized. The mixtures were injected and characterized. The TGA analyzes showed that the addition of nanoclay considerably increased the thermal stability of the samples, especially the PELBD/OMMT2,0, which increase was of 5.6\% compared to White. Through DSC it was found that the samples with nanoclay incorporation suffered no change in melting temperature in relation to the pure sample of LLDPE, however, the incorporation of clay increased the degree of crystallinity of the samples, especially for the LLDPE/OMMT2,5 sample that showed a 9,48\% degree of crystallinity higher than the white one. The flammability results revealed that the LLDPE/OMMT2,0 sample showed a decrease of $38 \%$ in the flame propagation velocity. In the tensile test it was noticed an increase in stiffness of the samples with addition of OMMT compared to the White one, increasing the Young's modulus and decreasing the elongation at fracture with the percentage increase of OMMT. On the other hand, the NMR technique showed that the samples
\end{abstract}


of up to 2,5\% of OMMT suggests the formation of an exfoliated nanocomposite.

Keywords: Polyethylene, organophilic montmorillonite, nanocomposite.

\section{INTRODUÇÃO}

Várias tecnologias vem se destacando na área de transformados plásticos, destaque para os processos e matérias primas, bem como na utilização de recursos e métodos de produção cada vez mais sofisticados. Neste contexto, a nanotecnologia desenvolveu-se na última década de maneira exponencial, envolvendo os mais diversos setores e permitindo a produção de novos materiais com propriedades até então, nunca antes alcançadas. Ela envolve a produção, o processamento e a aplicação de materiais com dimensões de 1 a $100 \mathrm{~nm}$ [2].

$\mathrm{O}$ uso de aditivos para reforçar e melhorar as características dos polímeros é uma tecnologia amplamente conhecida que tem sido aplicada durante décadas. A aplicação de nanotecnologia para reforçar os polímeros tem gerado muitas expectativas, já que demonstram ter capacidade de melhorar as propriedades gerais de forma significativa. Pode-se considerar ter um potencial solução para controlar a flamabilidade da matriz polimérica, reduzir custos, alterar propriedades reológicas dos polímeros, melhorar características visuais das peças produzidas, dentre outras propriedades a serem melhoradas [7].

Peças fabricadas de polímeros oriundos de fontes petroquímicas são amplamente utilizadas na vida cotidiana devido as características que as tornam atrativas para a maioria dos usos comuns à que estão associadas. Esses produtos se destacam por sua força e resistência, durabilidade, baixa densidade, excelente barreira contra água e gases, resistência a agentes químicos, excelente processabilidade e baixo custo [1].

Os nanocompósitos começaram a despertar interesse na década de 80 quando o Laboratório de Pesquisas da Toyota produziu um nanocompósito de poliamida e argila, utilizado na confecção de autopeças para o modelo Toyota Carmy [10]. Desde então, o desenvolvimento de nanocompósitos de matrizes poliméricas e nanopartículas inorgânicas tem sido o foco de pesquisas científicas, tendo em vista a necessidade de atender à crescente demanda por materiais com características de durabilidade a longo prazo, estabilidade térmica e dimensional, entre outras, impostas para muitas aplicações em engenharia [9]. Esses materiais se diferenciam dos compósitos convencionais por conta da grande interação interfacial gerada pela dispersão uniforme da nanocarga na matriz.

Materiais nanocompósitos produzidos com argilas são obtidos quase exclusivamente pela intercalação do polímero dentro das galerias dos silicatos. Há uma grande variedade de argilas (silicatos lamelares), sintéticas ou naturais, que são capazes de satisfazer as condições específicas, para intercalação dos polímeros. A ciência dos materiais, em particular, utiliza o termo nanocompósitos em duas áreas distintas: cerâmica e polímeros. Recentemente, muita atenção foi dada para os nanocompósitos poliméricos, especialmente para os polímeros com argilas naturais. Estes representam uma alternativa racional para polímeros convencionais, empregando uma mínima adição $(<6 \%)$ de argila, o que originam polímeros com maior dureza, maior viscosidade, melhor tenacidade, maior resistência ao fogo e a ignição, peso reduzido, melhorias nas propriedades mecânicas, boa transparência, maior estabilidade térmica, grande decréscimo na permeabilidade a gases, dentre outras propriedades [2].

Dentre os tipos de argila utilizados para a produção de nanocompósitos, a montmorilonita de origem natural merece destaque, pois apresenta razão de aspecto bastante elevada devido à sua excelente capacidade de delaminação, além de alta resistência a solventes e estabilidade térmica necessária aos processos de polimerização. Essa argila é composta por camadas estruturais constituídas por duas folhas tetraédricas de sílica e uma folha central octaédrica de alumina, que se mantêm unidas por átomos de oxigênio comuns a ambas as folhas. As dimensões laterais de uma folha variam desde $300 \AA$ até vários $\mu \mathrm{m}$, enquanto sua espessura pode chegar a 1 nanômetro. O empilhamento dessas placas é regido por forças polares relativamente fracas e por forças de van der Waals. A montmorilonita possui $80 \%$ dos cátions trocáveis nas galerias e $20 \%$ nas superfícies laterais. Apesar das suas qualidades, em seu estado natural é hidrofilica, o que a torna quimicamente incompatível com as cadeias poliméricas. Portanto, é necessário que essa argila sofra um processo de modificação artificial para torná-la organofílica, e desta forma, compatível com a matriz polimérica. As placas da montmorilonita apresentam perfil irregular, são muito finas e tem tendência a se agregarem no processo de secagem, e apresentam boa capacidade de delaminação quando colocada em contato com a água. [3].

A montmorilonita (MMT) é um argilomineral, cuja aplicação vem despertado interesse científico e tecnológico por proporcionar melhorias significativas quando incorporadas em materiais poliméricos puros e compósitos convencionais. O estudo de sua aplicação em termoplásticos vem sendo analisada constantemente, entretanto a utilização de fontes nacionais ainda foi pouco estudada. Estudos científicos mostram que a introdução de pequenos percentuais de uma fase inorgânica dispersa em escala nanométrica no polímero provoca melhorias significativas nas propriedades de barreira, resistência à chama, estabilidade térmica, 
resistência mecânica e resistência à degradação ambiental (raios ultravioleta e absorção de água), o que torna a MMT uma potencial candidata para aplicações que exijam alto desempenho [3].

Neste contexto, propõe-se neste projeto o estudo e caracterização da incorporação da argila organofílica em PELBD, visando a melhoria de propriedades físico-químicas nesse polímero, como processabilidade, retardância a chamas, resistência mecânica e resistência térmica, visando potenciais aplicações em peças injetadas para a linha automotiva e construção civil.

A aplicação da argila organofílica em uma matriz polimérica, a partir de resultados alcançados, pode auxiliar na melhoria de propriedades reológicas dos polímeros, redução de custos, entre outros pontos importantes, visando o aumento da qualidade na produção de peças plásticas e maior competitividade do produto no mercado.

Além dos benefícios que a aplicação da OMMT pode oferecer aos transformadores termoplásticos, o estudo neste projeto foi realizado em uma argila organofilica de origem nacional, que até então não possui registro para esse tipo de aplicação. As corporações optam pela utilização da argila importada, já que as de origem nacional não possuem uma qualidade constante em todos os lotes fabricados, o custo da argila nacional não se torna economicamente atrativa e no Brasil são pouquíssimas empresas que exploram essa tecnologia. Com isso, busca-se nesse estudo, além da análise da eficiência da OMMT aplicada em PELBD, o incentivo pela aplicação de argilas organofílicas nacionais ao invés de importadas.

\section{MATERIAIS E MÉTODOS}

\subsection{Materiais}

A OMMT foi fornecida pela Spectrochem, classificada como uma nanoargila organofílica de natureza química de silico aluminato de tetralquilamônio. A nanoargila possui dimensões entre 1 e $4 \mathrm{~nm}$ e densidade relativa de 1,5-1,7 $\mathrm{g} / \mathrm{cm}^{3}$. O polímero aplicado nos experimentos foi o Polietileno Linear de Baixa Densidade (PELBD) (IF33), fornecido pela Braskem. O índice de fluidez do PEBDL é de $48 \mathrm{~g} / 10 \mathrm{~min}$, densidade de $0,931 \mathrm{~g} / \mathrm{cm}^{3}$ temperatura de processo entre 150 e $210{ }^{\circ} \mathrm{C}$.

Com o intuito de auxiliar na compatibilização do PEBDL e a nanocarga foi empregado o agente compatibilizante fornecido pela Cristal Master com código 19569-PN, densidade de $0,9-1,10 \mathrm{~g} / \mathrm{cm}^{3}$, com capacidade de resistir a até $300{ }^{\circ} \mathrm{C}$. Como estabilizante térmico, foi utilizado o estearato de zinco (Zincum SW) fornecido pela empresa Baerlocher, aditivo de origem vegetal.

\subsection{Obtenção das amostras}

Primeiramente foi preparado um concentrado com o PEBDL, a argila, o agente compatibilizante e o estabilizante térmico. Esta mistura foi realizada em uma homogeneizadora modelo Drays $\mathrm{MH}$, a $120^{\circ} \mathrm{C}$ e a massa produzida foi prensada em uma prensa hidráulica da marca $\mathrm{MH}$, com aquecimento a $100{ }^{\circ} \mathrm{C}$. A placa obtida foi granulada por meio de uma guilhotina, obtendo-se o composto em pellets. Este concentrado passou novamente pelo mesmo processo para garantir a homogeneidade do sistema e correção da quantidade de cada componente na mistura. A Tabela 1 apresenta a composição de cada formulação e a Figura 1, o esquema empregado para a obtenção deste concentrado.

Tabela 1: Composição do compósito (primeira mistura) e nanocompósito (segunda mistura) produzidos.

\section{Argila (\%)}

Agente Compatibilizante

(\%)
PELBD

(\%)
Estearato de Zinco

(\%)

\begin{tabular}{lcccc}
\hline Concentrado & 40 & 10 & 47 & 3 \\
\hline $\begin{array}{l}\text { Concentrado repro- } \\
\text { cessado }\end{array}$ & 64 & 16 & 18,8 & 1,2
\end{tabular}

Fonte: Primária (2015). 


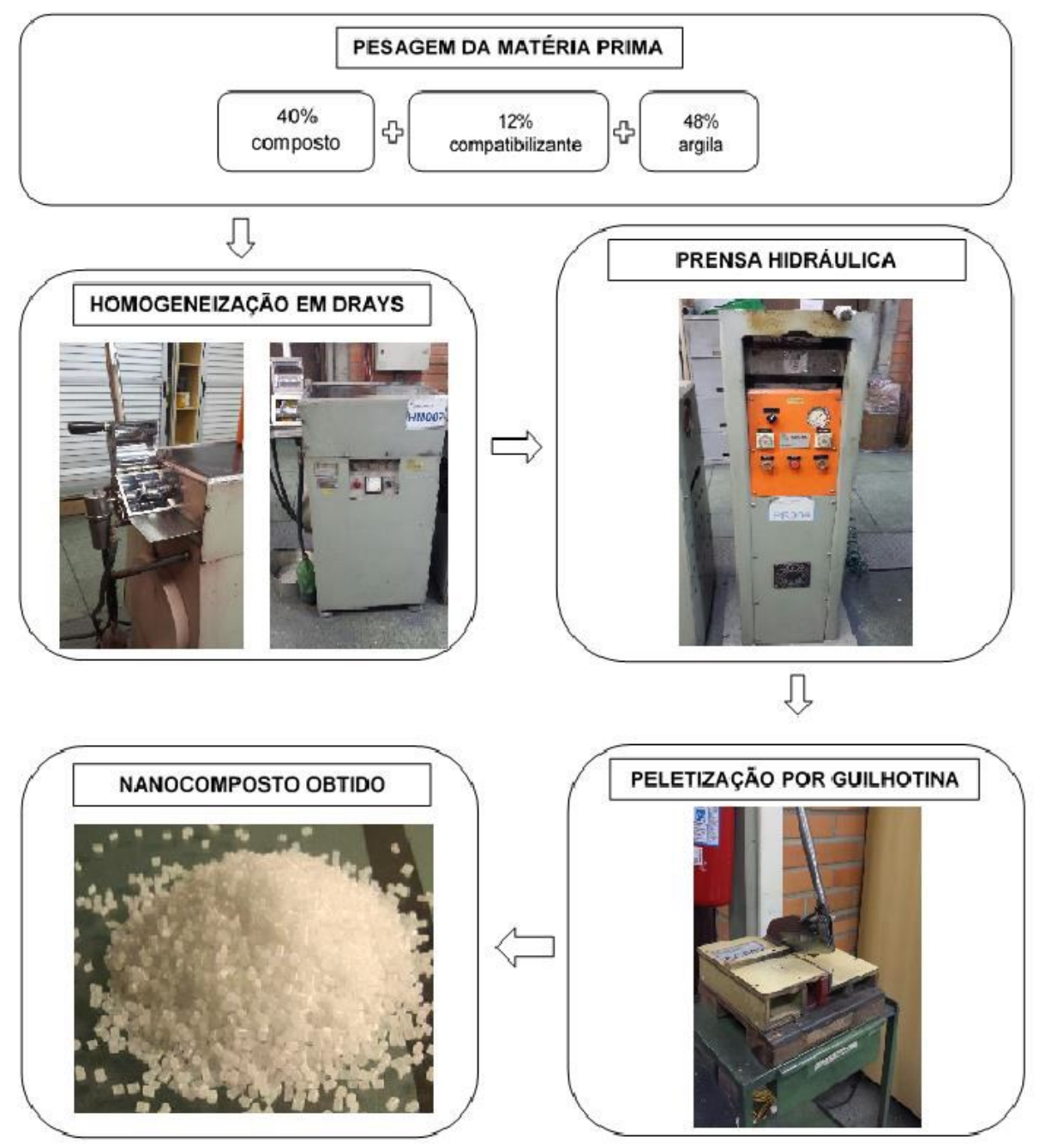

Figura 1: Fluxograma para obtenção do concentrado de PEBDL.

Para a obtenção dos nanocompótsitos, conforme as formulações descritas na Tabela 2 foi realizado o processo de injeção na injetora Sandretto do laboratório de trasnformação de materiais plásticos com temperatura de processamento entre $220{ }^{\circ} \mathrm{C}$ a $270{ }^{\circ} \mathrm{C}$ e tempo de injeção de $1,1 \mathrm{~s}$. As formulações foram injetadas em dois moldes, uma para atender os padrões do ensaio de tração e o outro para teste de flamabilidade. A injeção foi realizada no laboratório de transformação de materiais plásticos da UNISOCIESC.

Tabela 2: Formulação das amostras injetadas

\begin{tabular}{|ccccc} 
Matéria prima & PELBD (\%) & Nanoargila (\%) & $\begin{array}{c}\text { Agente compatibili- } \\
\text { zante }\end{array}$ & \multicolumn{2}{c}{ Estearato de zinco } \\
\hline PELBD/OMMT 0 & 99,35 & 0 & 0,15 & 0,5 \\
\hline PELBD/OMMT 2,0 & 97,35 & 2,0 & 0,15 & 0,5 \\
\hline PELBD/OMMT 2,5 & 96,85 & 2,5 & 0,15 & 0,5 \\
\hline PELBD/OMMT 3,0 & 96,35 & 3,0 & 0,15 & 0,5 \\
\hline PELBD/OMMT 3,5 & 95,85 & 3,5 & 0,15 & 0,5 \\
\hline
\end{tabular}

Fonte: Primária (2015). 


\subsection{Caracterização das amostras}

Através de ensaios físico-químicos, foi caracterizado os nanocompósitos conforme descrição a seguir.

Para a caracterização das amostras utilizou-se de algumas análises como, análise termogravimétrica (TGA), teste de queima (classificação UL 94), ensaio mecânico sob tração e microscopia eletrônica de varredura com emissão de campo (MEV FEG) e ressonância magnética nuclear (RMN). e ensaio de resistência a tração conforme as normas UL 94 e ASTM 638 (03),

Por meio de calorimetria exploratória diferencial (DSC) foi avaliado o grau de cristalinidade da mistura com relação a amostra padrão (chamada neste trabalho de Branco) e variação das temperaturas de fusão sendo determinados a temperatura de fusão, a entalpia de fusão e o grau de cristalinidade. As curvas de DSC foram conduzidas em um equipamento DSC-Q20/TA Instruments (Laboratório de Materiais/UNIVILLE) sob fluxo de nitrogênio. As amostras foram seladas em panelas de alumínio e aquecidas de 25 a $200{ }^{\circ} \mathrm{C}$ a uma taxa de aquecimento de $10{ }^{\circ} \mathrm{C} \mathrm{min}^{-1}$ (primeiro aquecimento) e mantidas a esta temperatura por 2 min. Subsequentemente, elas foram resfriadas rapidamente até $-90^{\circ} \mathrm{C}$ (jumping) e aquecidas novamente até $200{ }^{\circ} \mathrm{C} \min ^{-1}$ (segundo aquecimento).

Para avaliar a estabilidade térmica das amostras e o percentual de perda de massa em função da temperatura em uma atmosfera controlada foi realizado a termogravimetrias (TGA). As curvas de TGA foram obtidas em uma termobalança TGA-Q50/TA Instruments (Laboratório de Materiais/UNIVILLE). Em um porta-amostra de platina cerca de $0,5 \mathrm{mg}$ de cada amostra foi inserida e aquecidas de 25 a $1000{ }^{\circ} \mathrm{C}$, com taxa de aquecimento de $10{ }^{\circ} \mathrm{C}$ min-1 em atmosfera de nitrogênio. Os gráficos de análise foram gerados pelo software TA Instruments.

A efetividade das diferentes proporções de nanoargila como antichama aplicadas em PELBD foram avaliados por meio de ensaios de flamabilidade na horizontal, estes foram executados com base na norma UL 94. Todos os corpos de prova com o comprimento de $123 \mathrm{~mm}$ foram fixados em garras na posição horizontal alocados em capela para exaustão dos gases e fumaças liberadas durante a queima, sendo fixado um tempo de 2 min de ensaio. A norma UL 94 considera a avaliação por $10 \mathrm{~s}$, entretanto, nesse teste, foi estabelecido o tempo de 2 minutos devido à rapidez com que os corpos de prova queimaram. Os ensaios foram realizados em cinco corpos de prova e o ensaio foi realizado em triplicata - para cada amostra os cálculos da média e desvio padrão. $\mathrm{O}$ bico de Bunsen foi posicionado em ângulo de $45^{\circ}$ em relação ao corpo de prova. $\mathrm{O}$ fogo foi aproximado aproximada da amostra por $10 \mathrm{~s}$ e observado a formação de chamas no corpo de prova. O esquema da montagem do aparato está apresentado na Figura 2, na qual durante o teste acompanhou-se a perda de amostra com relação ao tempo de queima pelo comprimento do corpo de prova.

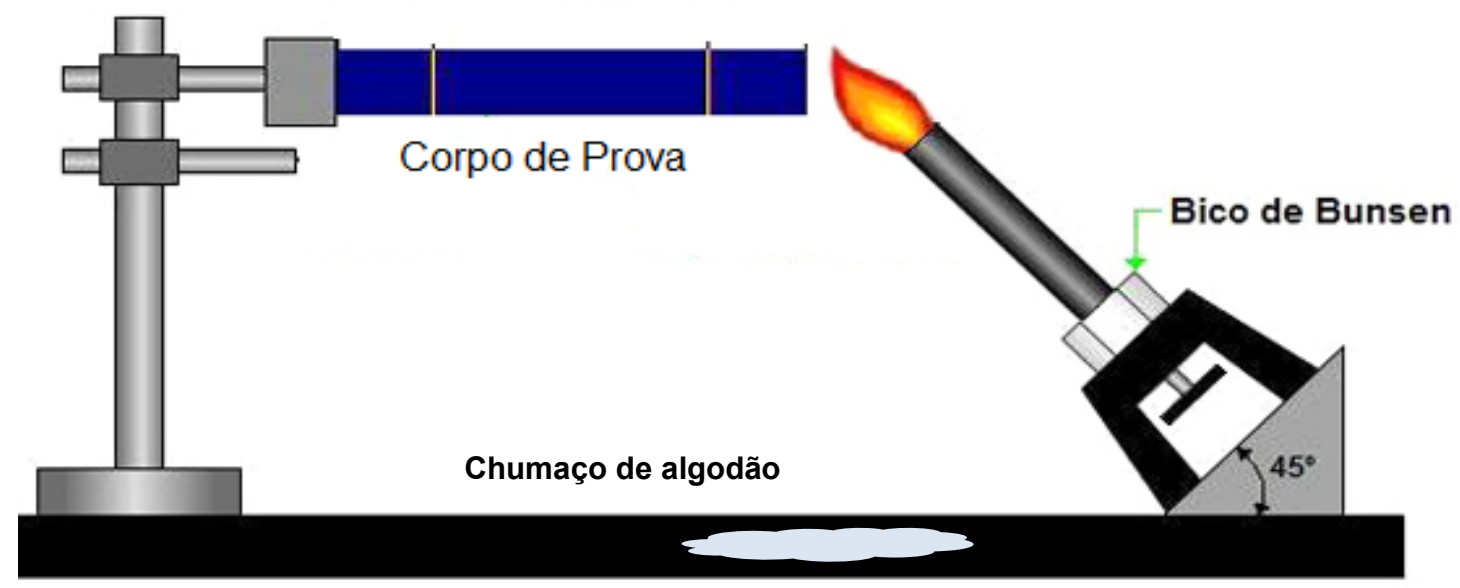

Figura 2: Esquema do teste da queima do corpo de prova na Horizontal, conforme norma UL94.

O ensaio de tração foi realizado em quintuplicata, com base na norma ASTM D 638, no Laboratório de Ensaios Mecânicos, CAMEGI da UNIVILLE. O equipamento utilizado foi a máquina de ensaio Universal EMIC modelo DL10000/700 com uma célula de carga de $500 \mathrm{~N}$ e velocidade de $500 \mathrm{~mm} \mathrm{~min}^{-1}$. Foram registrados todos os dados de resistência à tração e deformação na ruptura através do software TESC versão 1.13 .

A espectroscopia de RMN de baixa resolução em baixo campo é de baixa sensibilidade e, por isso, é utilizada na análise de substâncias químicas com composição de alta abundância natural e grande constante magnetogírica. No presente trabalho a ressonância magnética nuclear foi realizada no Laboratório de Solu- 
ções em Relaxometria - IMA da Universidade Federal do Rio de Janeiro. O equipamento utilizado foi o MARAN Ultra 0,54 (23,3 MHz para o $1 \mathrm{H})$ da marca Oxford Instruments com sonda de $18 \mathrm{~mm}$ e os resultados foram gerados no Software Winfit e OriginLab. A temperatura de realização do ensaio foi $30{ }^{\circ} \mathrm{C}$. Essa análise teve por objetivo a avaliação da intercalação da argila na massa polimérica, na qual pode ser classificada em fase separada, intercalada ou esfoliada/delaminada. Para a fase separada a estrutura da mistura é considerada um microcompósito convencional, já as fases intercaladas e esfoliadas a estrutura é considerada como um nanocompósito (objetivo deste projeto).

A avaliação da morfologia dos nanocompósitos foi feita por meio de Microscopia Eletrônica de Varredura com Emissão de Campo (FEG) do laboratório da UDESC. A microscopia foi realizada em microscópio Jeol JSM 6701F, com amperagem máxima de $10 \mu \mathrm{A}$, e distância focal de $3 \mathrm{~mm}$. Utilizou-se recobrimento de ouro por eletrodeposição sobre as amostras. As amostras caracterizadas por FEG foram fraturadas criogenicamente, de forma a realizar-se fratura frágil para a análise da superfície. O tempo de imersão das amostras no nitrogênio foi de 5 minutos, sendo realizado um vinco com estilete na amostra, de modo a criar uma linha de ruptura, facilitando o alinhamento da região de fratura. Todas as amostras foram suspensas em água e submetidas a homogeneização manual (normal) e em ultrassom sob diferentes tempos.

Foi observado durante o processamento das amostras, que na produção do composto a massa polimérica não estava bem homogênea com a OMMT incorporada. Entretanto, na produção do nanocomposto verificou-se uma massa homogênea, na qual aparentemente a argila havia sido incorporada.

\section{RESULTADOS E DISCUSSÃO}

\subsection{Caracterização das amostras}

\subsubsection{Calorimetria Exploratória Diferencial (DSC)}

As curvas do DSC obtidas no $1^{\circ}$ e $2^{\circ}$ aquecimento são mostradas na Figura 3 e os dados obtidos estão relacionados na Tabela 3. Para a amostra do Branco foi determinada a temperatura de fusão $\left(\mathrm{T}_{\mathrm{m}}\right)$ em $120,5^{\circ} \mathrm{C}$, valor esse que está dentro do valor do PELBD puro encontrado na literatura $\left(120\right.$ a $\left.130^{\circ} \mathrm{C}\right)[4]$. As amostras com incorporação de nanoargila apresentaram $\mathrm{T}_{\mathrm{m}} \mathrm{em}$ cerca de $120^{\circ} \mathrm{C}$, muito próximo ao valor do PELBD puro. Independentemente do teor de nanoargila adicionado na formulação, não foi possível perceber mudanças significativas nas temperaturas de transição das amostras quando comparando com os nanocompósitos. Para este teste, em função da quantidade de amostra, não é possível afirmar se a presença de nanoargila interfere ou não nas forças intermoleculares das cadeias do polímero, em função da não alteração das temperaturas de fusão das formulações.

A entalpia de fusão $\Delta \mathrm{H}_{\mathrm{m}}$ correspondente à área do pico, a qual foi utilizada no cálculo do grau de cristalinidade $\left(\boldsymbol{\alpha}_{\boldsymbol{c}}\right)$ através da razão de $\Delta \mathrm{H}_{\mathrm{m}} / \Delta \mathrm{H}_{\mathrm{m}}{ }^{\circ}$ multiplicado por 100, onde $\Delta \mathrm{H}_{\mathrm{m}}$ é a entalpia de fusão do PELBD obtidas por DSC, e $\Delta \mathrm{H}_{\mathrm{m}}{ }^{\circ}$ é a entalpia de fusão para o PEAD $100 \%$ cristalino, cujo valor é igual a $293 \mathrm{~J} / \mathrm{g}$ [8]. O PELBD puro apresentou $\alpha \mathrm{c}=47,71 \%$, enquanto o aumento percentual de nanoargila aumentou o grau de cristalinidade das amostras, com destaque para a amostra PELBD/OMMT 2,5\% que apresentou grau de cristalinidade $\alpha c=52,73 \%$. Percebe-se esse aumento no grau de cristalinidade na Figura 3a. O aumento de $10 \%$ no grau de cristalinidade pode estar relacionado ao fato da nanoargila agir como u, agente nucleante na massa polimérica. Esse aumento do grau de cristalinidade pode conferir ao polímero maior densidade e maior resistência à tração, devido ao empacotamento das macromoléculas. Mariano (2012) avaliou amostras de PEAD e bentonita tratada com sal cloreto de alquildimetilbenzilamônio, na qual observou grau de cristalinidade do nanocompósito incorporado a $2 \%$, menor que o PEAD puro devido a formação de cristais foi afetada pelo teor de argila. 
a)

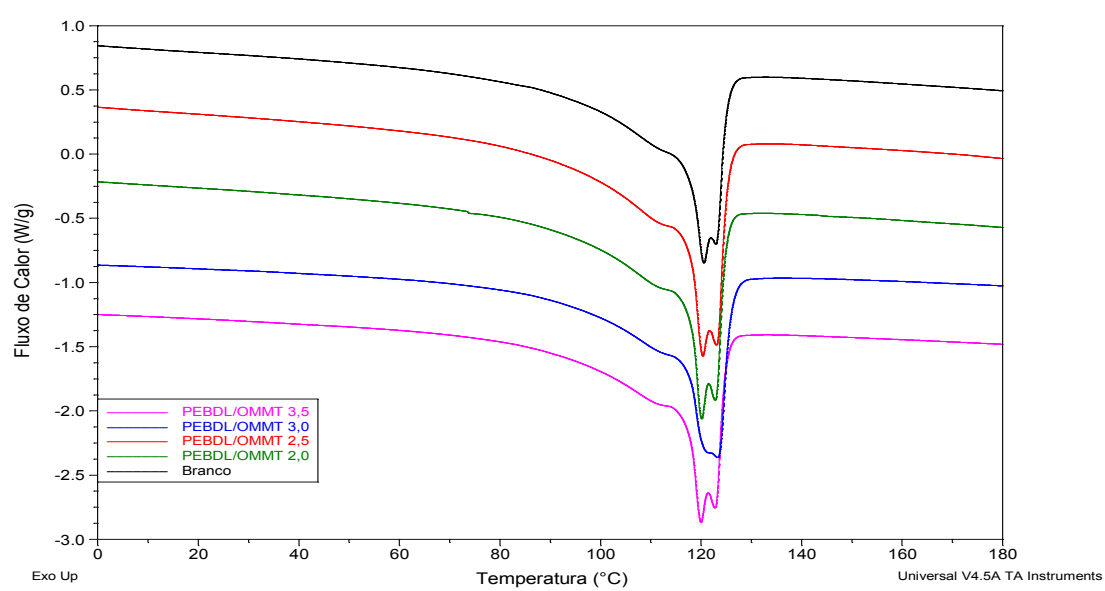

b)

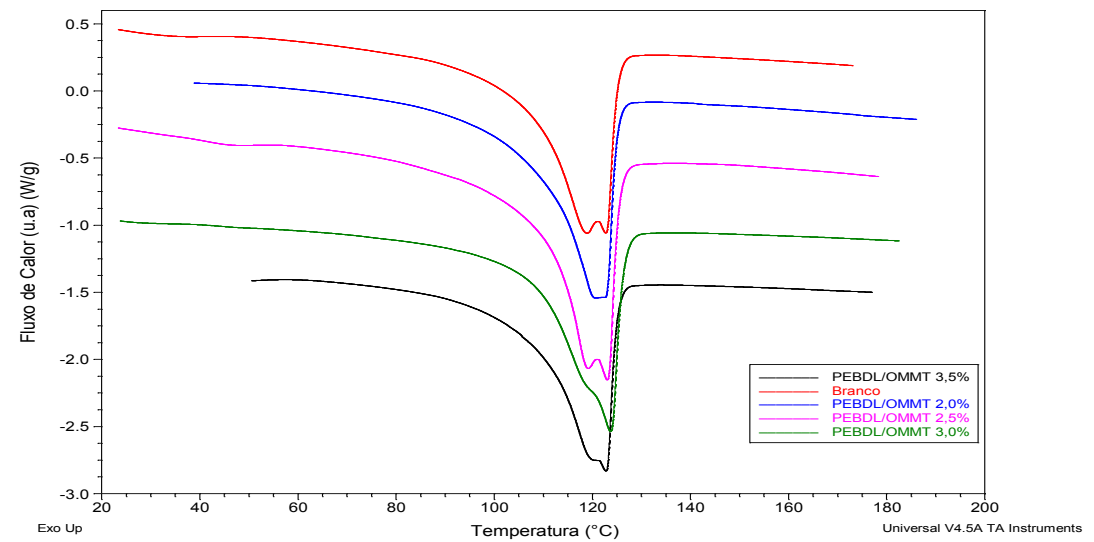

Figura 3: Curvas de DSC do primeiro e segundo aquecimento para as amostras de PELBD sem adição de nanoargila (Branco) e nanocompósitos de PELBD/OMMT 2,0; PELBD/OMMT 2,5; PELBD/OMMT 3,0 e PELBD/OMMT 3,5 a) Primeiro aquecimento b) segundo aquecimento.

Tabela 3: Dados de $T_{m}, \Delta H_{m}$ e ac para as amostras de PELBD puro e nanocompósitos de PELBD/OMMT 2,0; PELBD/OMMT 2,5; PELBD/OMMT 3,0 e PELBD/OMMT 3,5.

\begin{tabular}{c|c|c|c|c|c}
\hline Amostra & $\left.\mathbf{T}_{\mathbf{m} \mathbf{1}}{ }^{(} \mathbf{C}\right)$ & $\left.\mathbf{T}_{\mathbf{m} \mathbf{2}}{ }^{\circ} \mathbf{C}\right)$ & $\boldsymbol{\Delta H}_{\mathbf{m}}\left(\mathbf{J ~ g ~}^{-\mathbf{1}}\right)$ & ${ }^{*} \Delta \mathbf{H}_{\mathbf{m}}\left(\mathbf{J ~ g}^{-\mathbf{1}}\right)$ & $\boldsymbol{\alpha}_{\mathbf{c}}$ \\
\hline BRANCO & 120,5 & 123,1 & 138,9 & 139,3 & 47,7 \\
\hline PELBD/OMMT 2,0 & 120,1 & 123,0 & 146,1 & 142,2 & 49,9 \\
\hline PELBD/OMMT 2,5 & 120,3 & 123,3 & 154,5 & 149,6 & 52,7 \\
\hline PELBD/OMMT 3,0 & 120,3 & 123,3 & 147,6 & 142,2 & 50,4 \\
\hline PELBD/OMMT 3,5 & 120,0 & 123,0 & 141,3 & 135,4 & 48,2 \\
\hline
\end{tabular}

$* \Delta \mathrm{Hm}\left(\mathrm{J} \mathrm{g}^{-1}\right)=$ entalpia de fusão levando em consideração o percentual de PELBD na amostra.

Fonte: Primária (2015).

\subsubsection{Análise Termogravimétrica}

A Figura 4 ilustra as curvas termogravimétricas (curvas TG) e as curvas da primeira derivada das curvas termogravimétricas (curvas DTG) obtidas por TGA com auxílio do software da TA Instruments. Os dados obtidos a partir destas curvas estão relacionados na Tabela 4. As temperaturas de onset $\left(\mathrm{T}_{\text {onset }}\right)$ e os percentuais de perda de massa foram determinados a partir das curvas TG (Figura 4a), enquanto as temperaturas máximas de degradação ( $T_{\text {máx }}$ ) foram obtidas por meio das curvas DTG (Figura 4b). 
a)

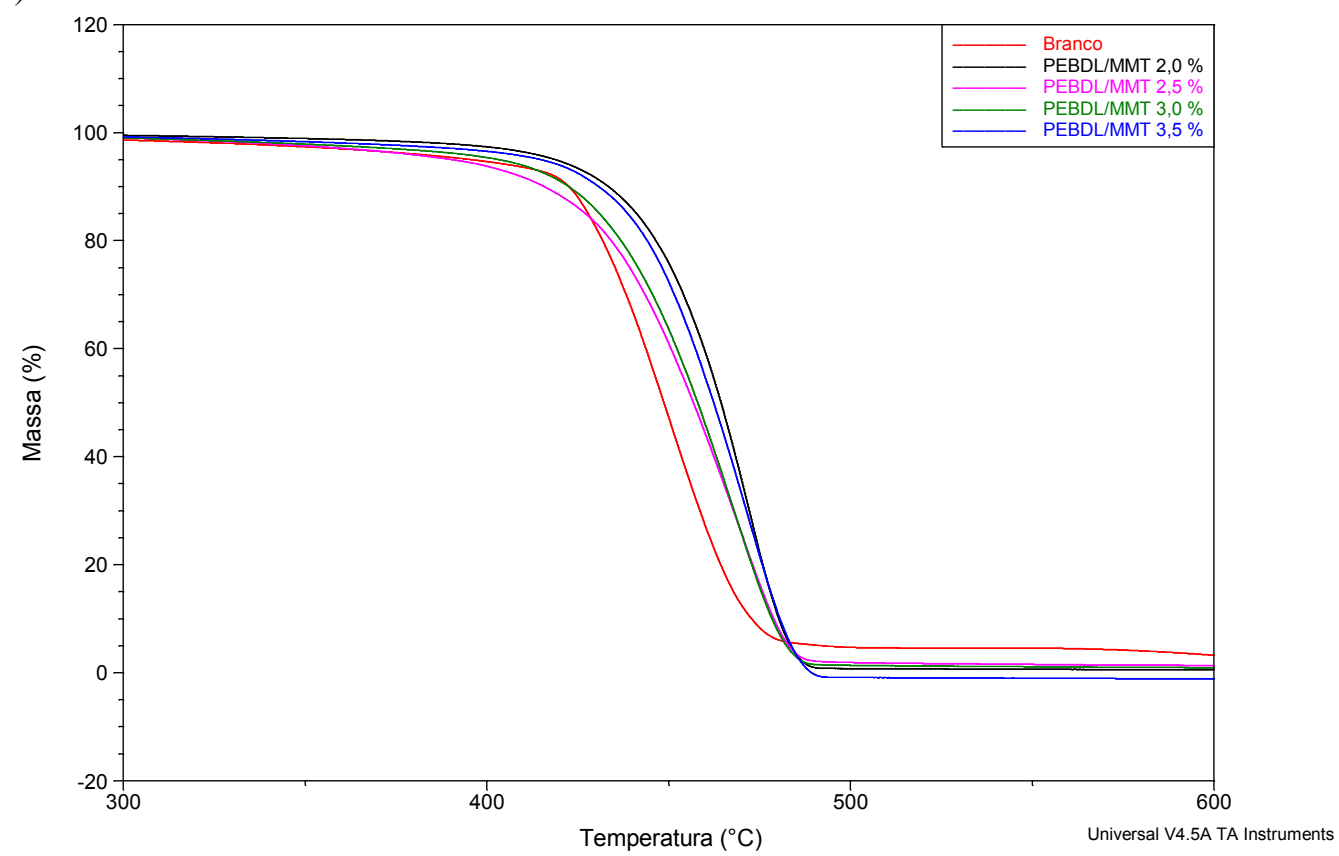

b)

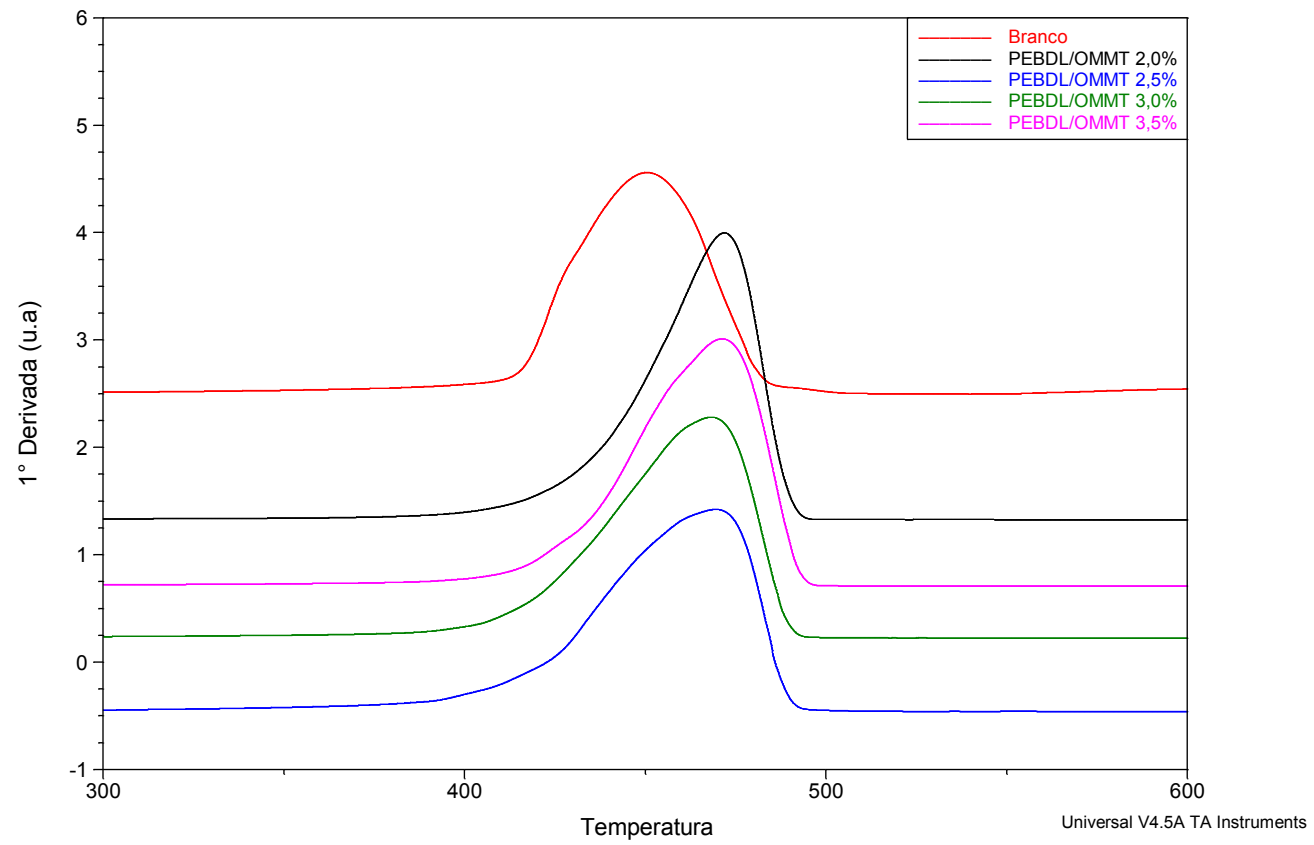

Figura 4: Curvas de TGA para as amostras sintetizadas com Branco (sem adição de nanoargila) e PELBD/0MMT (2,0; $2,5 ; 3,0$ e 3,5$)$. a) curvas TG; b) curvas DTG.

As curvas com adição de montmorilonita (PELBD/OMMT) apresentaram apenas um estágio de decomposição térmica. Observa-se então que a adição de nanoargila promoveu um aumento na $\mathrm{T}_{\text {onset }}$ das amostras. Com apenas 2,0\% de OMMT houve um aumento de $19,9{ }^{\circ} \mathrm{C}$ na estabilidade térmica do PELBD, enquanto que com a adição de $2,5 \%$ de OMMT a $\mathrm{T}_{\text {onset }}$ apresentou um aumento de $7,8{ }^{\circ} \mathrm{C}$ em comparação ao branco. A amostra com 3,0\% de OMMT apresenta aumento em apenas $4^{\circ} \mathrm{C}$ e a $3,5 \%$ de OMMT apresentou um aumento na estabilidade de $11^{\circ} \mathrm{C}$. 
Tabela 4: Dados de perda de massa, $\mathrm{T}_{\text {onset }}$ e $\mathrm{T}_{\text {máx }}$ obtidos das curvas de TGA para as amostras BRANCO, PELBD/OMMT $(2,0 ; 2,5 ; 3,0$ e 3,5$)$.

\begin{tabular}{c|c|c|c}
\hline Amostra & $\begin{array}{c}\mathbf{T}_{\text {onset }} \\
\left({ }^{\circ} \mathbf{C}\right)\end{array}$ & $\begin{array}{c}\text { Perda de } \\
\text { massa (\%) }\end{array}$ & $\begin{array}{c}\mathbf{T}_{\text {máx }} \\
\left({ }^{\circ} \mathbf{C}\right)\end{array}$ \\
\hline BRANCO & 425,0 & 96,6 & 450,5 \\
\hline PELBD/OMMT 2,0 & 444,9 & 98,0 & 471,8 \\
\hline PELBD/OMMT 2,5 & 432,8 & 98,0 & 469,5 \\
\hline PELBD/OMMT 3,0 & 429,7 & 98,6 & 468,2 \\
\hline PELBD/OMMT 3,5 & 436,1 & 100,6 & 471,2 \\
\hline
\end{tabular}

Observando a Tabela 4 pode-se perceber a grande diferença no aumento de estabilidade térmica entre as amostras com adição de nanoargila e sem, como por exemplo a amostra com 2,0 \% que apresentou um aumento de $19,9^{\circ} \mathrm{C}$ na resistência térmica e consequentemente uma menor perda de massa. Todas as amostras com diferentes percentuais de nanoargila apresentaram um aumento na resistência térmica, já a maior perda de massa das amostras com percentuais acima de 2,5\% sugere uma má homogeinização das amostras, ou até mesmo pelo fato de que concentrações elevadas de nanoargila podem prejudicar a estrutura do polimero, na qual também é visualizado no ensaio MEV/FEG realizado.

\subsubsection{Teste de queima (classificação UL 94)}

Foram determinados os dados de comprimento de cada amostra, para o cálculo da média e desvio padrão da velocidade de propagação da chama dos ensaios realizados em triplicata, conforme ilustrado na Figura 5.

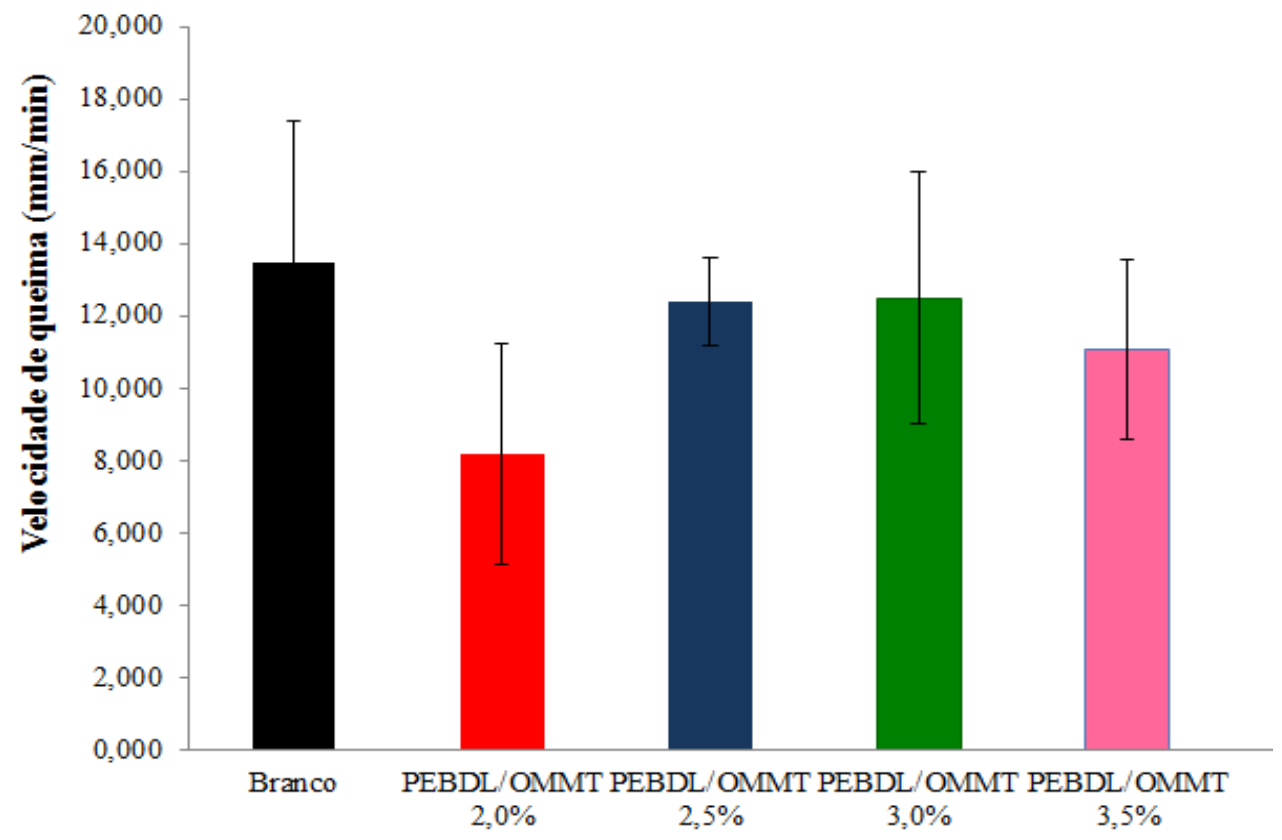

Figura 5: Velocidade de queima $(\mathrm{mm} / \mathrm{min})$ dos corpos de prova.

A amostra sem nanocarga apresentou um gotejamento contínuo do material, emissão de fumaça e altura elevada em comparação com as demais amostras, característica típica do polietileno.

A velocidade de propagação da chama para a amostra Branco foi de 13,5+-3,9 mm/min. O corpo de prova com 2,0 \% de nanoargila apresentou velocidade de $8,2 \mathrm{~mm} / \mathrm{min}$, ou seja, alcançando uma diminuição de $37,77 \%$ na velocidade de propagação de chama. Para percentuais de nanoargila superiores a $2 \%$ os valores obtidos foram muito similares ao Branco 
Analisando os resultados, apesar da formulação com $2 \%$ de nanocarga apresentar tempo de queima menor, quando analisado o desvio padrão, não é constatado variação significativa entre as diferentes formulações. Acredita-se que a presença da nanocarga nestas formulações não apresentou o efeito de retardante de chama como esperado. E isto pode estar ao fato do processo de transformação empregado, esfoliação das nanocarga, quantidade de nanocarga e até mesmo a origem da nanocarga.

A inflamabilidade do corpo de prova é devido à formação de uma camada termicamente isolante, gerada pelas nanopartículas de argila organofílica que protegem a matriz polimérica, proporcionando um efeito de barreira aos produtos voláteis gerados durante a combustão do nanocompósito, impedindo os mesmos de escapar e alimentar a chama. Assim, percebe-se que a adição e 2,0 \% de argila organofílica ao PELBD provocou o melhor resultado no processo de queima dos corpos de prova. Esses resultados estão de acordo com os apresentados por termogravimetria, pois as amostras com diferentes percentuais de OMMT, mostraram estabilidade térmica superior a amostra Branco (sem adição de OMMT).

Entretanto, os valores obtidos nos testes realizados não classificam a argila organofílica como um retardante de chamas nos percentuais aplicados (V-0, V-1 e V-2), conforme norma UL-94, persistindo a queima acima de 30 segundos para todas as amostras. Para que o nanocompósito seja considerado como um retardante de chamas, a queima do corpo de prova não deve persistir após 30 segundos.

\subsubsection{Ensaio mecânico sob tração}

Em alguns trabalhos é demonstrado que nanocompósitos de polímero-argila melhoram nas propriedades mecânicas quando comparados ao polímero puro. As Figuras 6, 7 e 8 apresentam, respectivamente, os resultados de resistência à tração, módulo de Young e alongamento na ruptura, para os corpos de prova de PELBD com diferentes percentuais de OMMT, referente os ensaios realizados em triplicata.

É possível verificar que houve um efeito significativo com a adição da OMMT com relação aos valores do PELBD puro encontrado na literatura (Características do PELBD no catálogo do fornecedor BRASKEM) e comparando também com o teste da amostra Branco, nota-se uma grande diferença de valores.

Na Figura 6, observa-se o resultado de resistência à tração obtido da amostra PELBD/OMMT 2,0 \% foi de 13,08 \pm 0,68 Mpa. Comparando com o valor fornecido pelo fabricante de 10,0 MPa percebe-se uma diferença de 3,0 MPa, (BRASKEM, 2015), e em relação a amostra sem adição de nanoargila que apresentou $9,90 \pm 0,62 \mathrm{Mpa}$ a diferença é de 3,18 MPa. Os valores de resistência à tração independente da adição de OMMT foram todos superiores ao branco, com destaque para a amostra com 2,5\% de OMMT que apresentou aumento de 4,21 MPa.

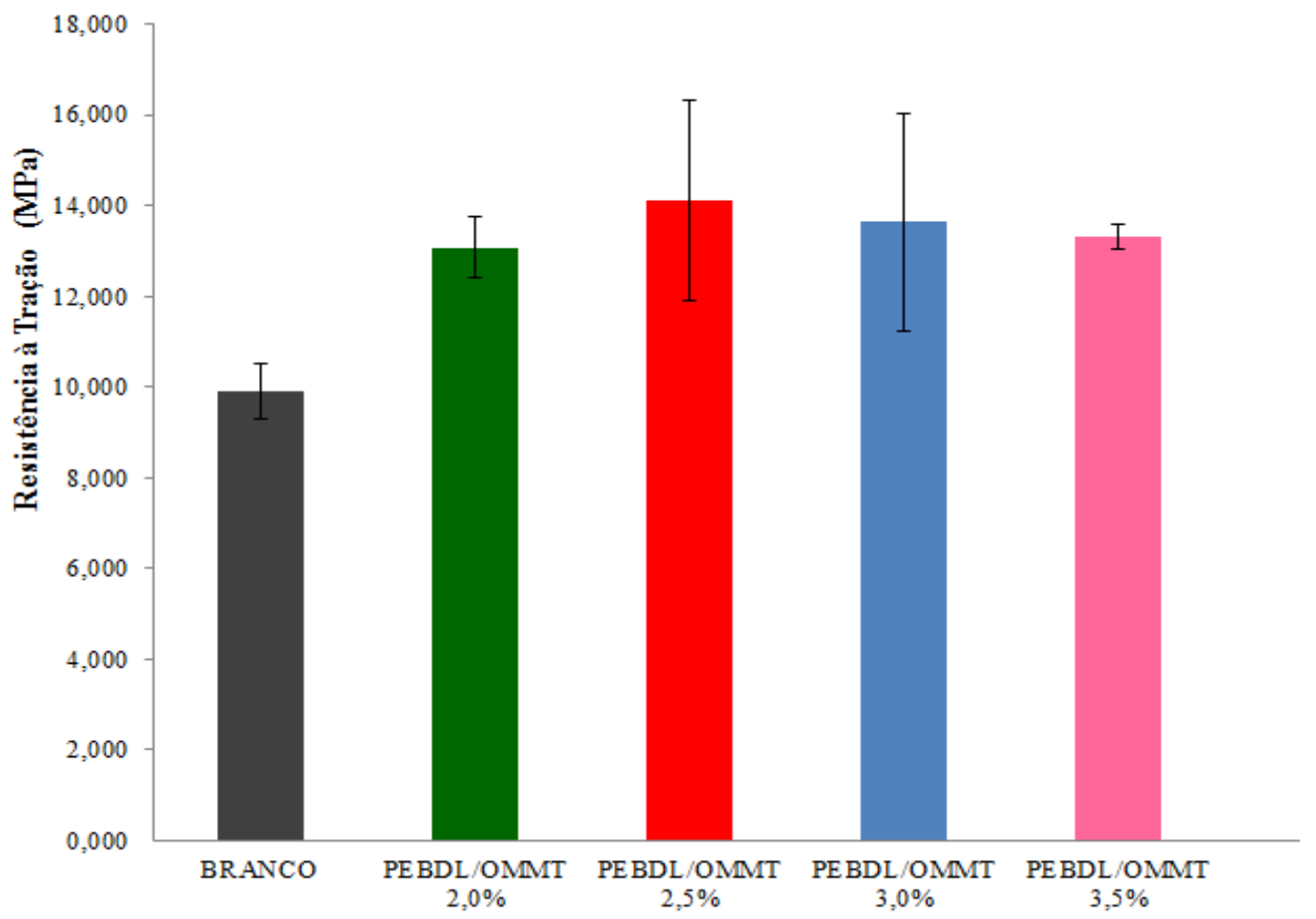

Figura 6: Resultados de resistência a tração obtidos por ensaio de tração do PELBD puro e das amostras PELBD/OMMT 
Na Figura 7 são apresentados os valores do módulo de elasticidade ou módulo de Young realizados em triplicata. Nota-se que a incorporação de OMMT promove um aumento do módulo de Young, por conta do efeito de reforço, valores esses que são consideráveis. A amostra sem adição de nanoargila apresentou módulo de 58,75 MPa, já a amostra 2,0\% de OMMT o Módulo de elasticidade apresentado foi de $526 \mathrm{MPa}$, ou seja, o módulo de elasticidade das amostras com a adição de OMMT melhorou muito, pois todos os valores foram superiores a $500 \mathrm{MPa}$.

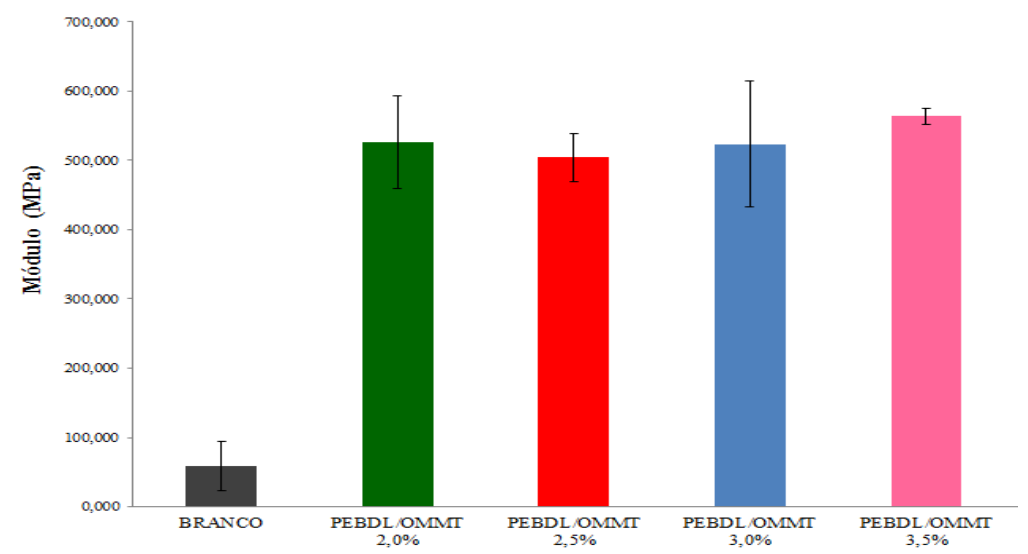

Figura 7: Resultados de módulo obtidos por ensaio de tração do PELBD puro, e PELBD/OMMT

Os valores apresentados na Figura 8 são referentes ao aumento do módulo de elasticidade dos corpos de prova que contém diferentes percentuais de nanoargila. Esse aumento do módulo de elasticidade ocorre devido ao fato da adição de nanoargila proporcionar um aumento da rigidez dos corpos de prova, atuando como reforço.

Na Figura 8 nota-se que o alongamento na ruptura teve uma redução significativa comparando os valores apresentados no ensaio. A amostra do Branco apresentou 128,30 \%, já as amostras com 2,0, 2,5, 3,0 e $3,5 \%$ de OMMT apresentaram alongamento na ruptura de 27,66, 23,58, 17,78 e 30,68, onde a amostra de 3,0 \% se destaca na diminuição. Essa redução do alongamento de ruptura é indicativo de fragilização é devido à presença de nanoargila no meio da matriz polimérica.

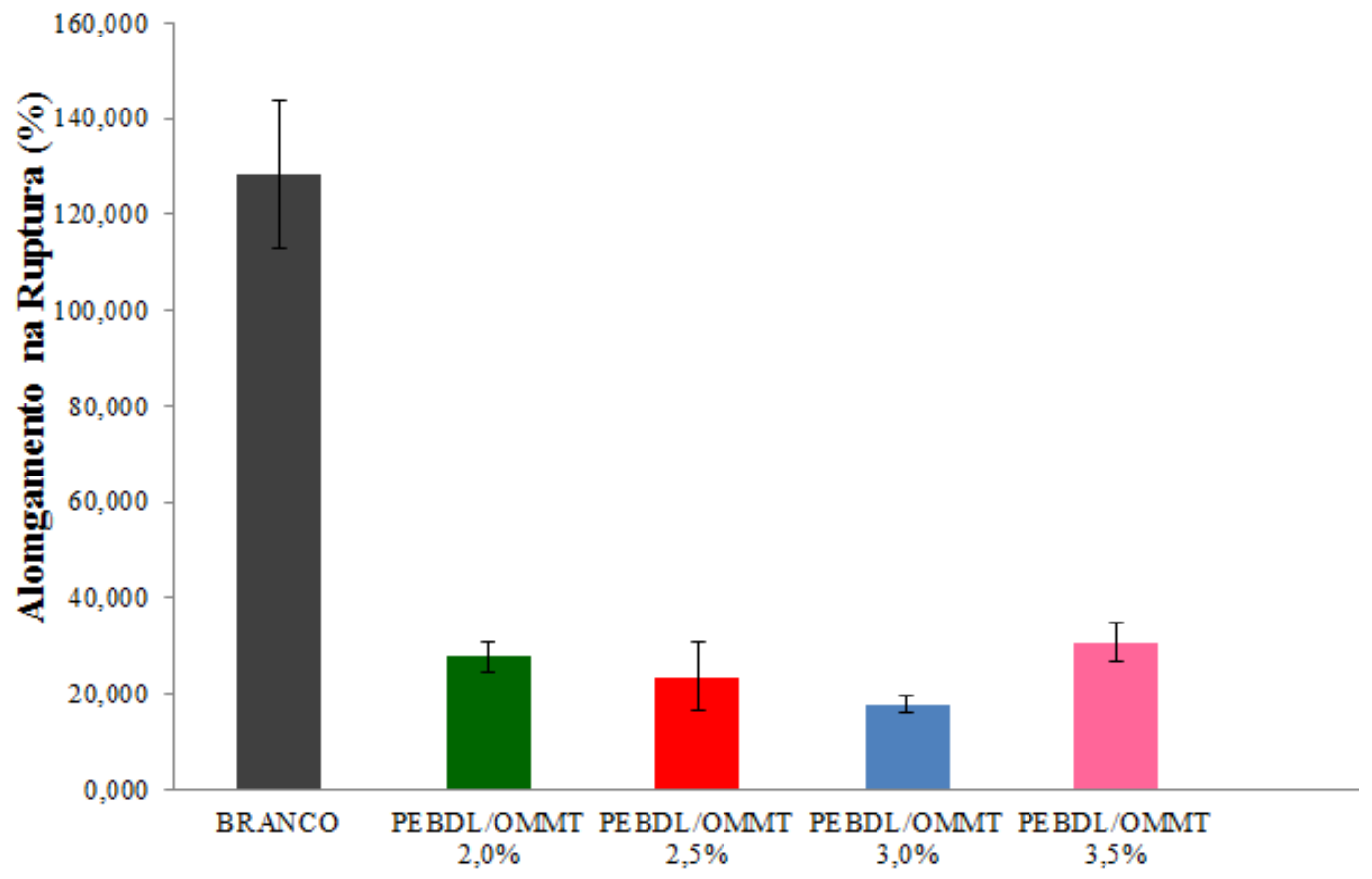

Figura 8: Resultados de alongamento na ruptura obtidos por ensaio de tração do PELBD puro e do PELBD/OMMT. 
A diminuição no alongamento na ruptura está relacionada ao aumento no modulo de elasticidade, pois as amostras que contém nanoargila incorporada, apresentaram aumento de rigidez e consequentemente diminui o alongamento na ruptura.

Durante as análises do ensaio de tração percebe-se que os resultados não apresentam uma tendência, isso acontece devido à má homogeneização da massa produzida para a obtenção dos corpos de prova, na qual foi comprovado por meio do ensaio MEV/FEG. Na Tabela 5, pode-se observar nitidamente a diferença entre as amostras sem adição da OMMT e as amostras com a incorporação da mesma.

Tabela 5: Valores das Propriedades mecânicas apresentadas pelo ensaio de Tração nas amostras.

\begin{tabular}{c|c|c|c} 
Amostra & Resistência a Tração & Módulo de Elasticidade & Alongamento na Ruptura \\
\hline BRANCO & $9,905 \pm 0,62$ & $58,75 \pm 34,92$ & $128,3 \pm 15,36$ \\
\hline PELBD/OMMT 2,0\% & $13,08 \pm 0,69$ & $526 \pm 66,47$ & $27,66 \pm 3,25$ \\
\hline PELBD/OMMT 2,5\% & $14,11 \pm 2,22$ & $504,1 \pm 35,03$ & $23,58 \pm 7,09$ \\
\hline PELBD/OMMT 3,0\% & $13,64 \pm 2,39$ & $523,5 \pm 90,82$ & $17,78 \pm 1,7$ \\
\hline PELBD/OMMT 3,5\% & $13,31 \pm 0,27$ & $564 \pm 11,67$ & $30,68 \pm 4,04$ \\
\hline
\end{tabular}

\subsubsection{Ressonância Magnética Nuclear (RMN)}

As curvas de domínios obtidos pela técnica RMN da PELBD e OMMT puros e seus nanocompósitos PELBD/OMMT obtidos em diferentes proporções de OMMT estão apresentados na Figura 9, enquanto os valores de tempo de relaxação $\left(\mathrm{T}_{1} \mathrm{H}\right)$ são apresentados na Tabela 6.

$\mathrm{O} \mathrm{T}_{1} \mathrm{H}$ médio foi obtido a partir das curvas de relaxação através da função: $\mathrm{M}=\mathrm{M}_{0}{ }^{(-\mathrm{t} / \mathrm{T} 1)}$. Este ajuste foi feito com o software OringLab Origin Pro 8.5 onde $\mathrm{M}$ é o sinal de magnetização, $\mathrm{M}_{0}$ é a magnetização inicial, t são os valores de tempo de espera entre o pulso de 180 e 90 graus e $\mathrm{T}_{1} \mathrm{H}$ é o tempo de relaxação médio (que consta na tabela). Nas amostras de até 2,5\% de OMMT percebe-se uma queda relativamente linear do $\mathrm{T}_{1} \mathrm{H}$, em virtude da característica paramagnética da argila que aumenta a mobilidade das cadeias de PELBD que estão próximas a superfície das lamelas, ou seja, há um aumento no espaço livre entre as cadeias, facilitando a movimentação, o que sugere a formação de um nanocompósito esfoliado ou com alto grau de esfoliação.

$\mathrm{O}$ aumento percentual de argila seguido da queda de $\mathrm{T}_{1} \mathrm{H}$ indica uma predominante esfoliação da OMMT. Na amostra com 3,0 \% de OMMT o valor de $\mathrm{T}_{1} \mathrm{H}$ continua diminuindo e com 3,5\% diminui bruscamente. Ou seja, para esse sistema, 3\% de adição é o limite de OMMT, pois é onde a esfoliação ainda predomina. Acima disso, a argila começa a aglomerar na matriz já saturada. Esses aglomerados acabam por desempenhar um efeito indesejado, atuando como falhas na matriz ou pontos de fragilidade, o que faz o $\mathrm{T}_{1} \mathrm{H}$ despencar. Além disso, grandes aglomerados de argila concentram muito mais seu efeito paramagnético de regiões pontuais, característica de predominante intercalação.

Um parâmetro muito importante que pode ser observado neste trabalho, é o estreitamento ou alargamento da curva de domínio. Um nanocompósito intercalado gera uma curva de domínio mais estreita, devido à manutenção da organização lamelar da argila. Em contrapartida, quando ocorre um aumento do espaçamento interlamelar a ponto de deixar as lamelas da argila mais "desorganizadas", a curva de domínio deste material é mais larga, caracterizando assim um nanocompósito esfoliado. Este comportamento foi observado em todas as amostras, sendo que aquelas que apresentaram valores de $\mathrm{T}_{1} \mathrm{H}$ maiores, apresentaram uma curva de domínio mais larga; e aquelas que apresentaram valores de $\mathrm{T}_{1} \mathrm{H}$ menores apresentaram uma curva de domínio mais estreita, sendo que o nanocompósito que apresentou uma curva de domínio mais larga foi o PELBD/OMMT 2,0 \% conforme mostrado na Figura 9.

Relata-se também a existência de domínios menores com tempos de relaxação também menores, em todas as amostras que foram analisadas. Para o PELBD este domínio pode ser atribuído a uma pequena porção mais flexível do material, já que se trata que um polímero semicristalino, com regiões amorfas que levarão a tempos de relaxação menores; e regiões cristalinas, que levarão a tempos de relaxação maiores. Já para os nanocompósitos pode-se observar o alargamento deste domínio ou o seu desmembramento, o que pode ser atribuído à presença de nanoargilas também nessa região mais flexíveis do PELBD. 


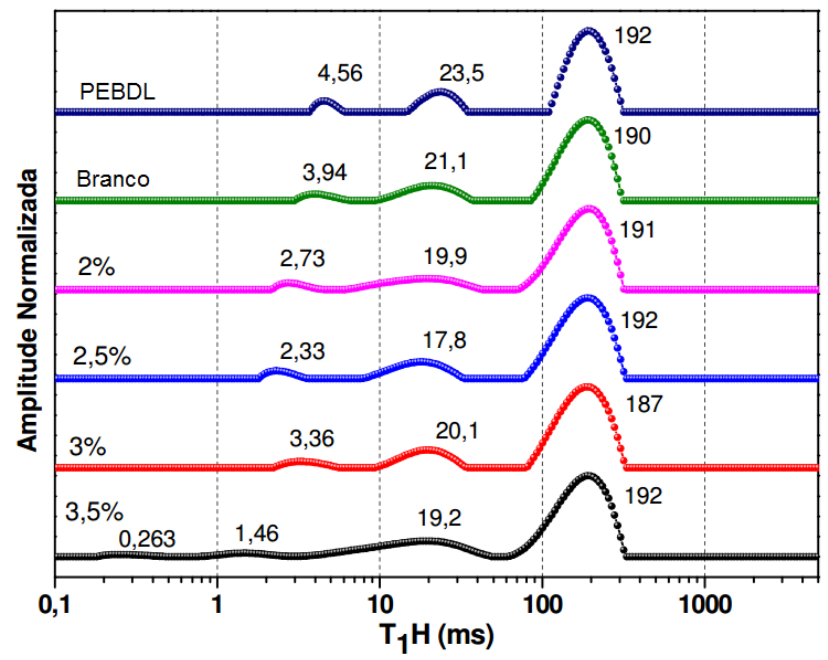

Figura 9: Curvas de distribuição de domínios de relaxação longitudinal obtidas por inversão-recuperação.

Tabela 6: Valores de $\mathrm{T}_{1} \mathrm{H}$ do PELBD, das amostras Branco (sem adição de OMMT) e PELBD/OMMT 2,0; 2,5; 3,0 e 3,5 $\%$.

\begin{tabular}{c|c}
\hline Amostra & $\mathbf{T}_{\mathbf{1}} \mathbf{H}$ \\
\hline PELBD & 131 \\
\hline Branco & 124 \\
\hline $2,0 \%$ & 123 \\
\hline $2,5 \%$ & 120 \\
\hline $3,0 \%$ & 121 \\
\hline $3,5 \%$ & 103 \\
\hline
\end{tabular}

\subsubsection{Microscopia Eletrônica de Varredura com Emissão de Campo (MEV FEG)}

Pode-se observar os resultados de MEV/FEG dos nanocompósitos com as variedades de argila na Figura 10. As imagens mostram que a argila normal, somente suspensa em água, com agitação manual, apresenta-se agregada. Entretanto, ao submetê-la ao ultrassom, ocorre a separação dos agregados e possivelmente a delaminação, por ser hidrofílica em um fluido hidrofílico. Espera-se que em fluidos hidrofóbicos, a argila se mantenha agregada e sem delaminação, porém, o fornecimento de energia (como o cisalhamento) pode causar delaminação. Conforme indicado na Figura 10, observam-se diversos pontos mal dispersos da argila incorporada no polímero, na qual permaneceu intercalado, ou seja, as amostras analisadas apresentaram ineficiência na homogeneização na injeção das peças, já que a força de cisalhamento da injetora não é uniforme, e então parte das partículas de argila delaminaram e outra parte permaneceu agregada. 


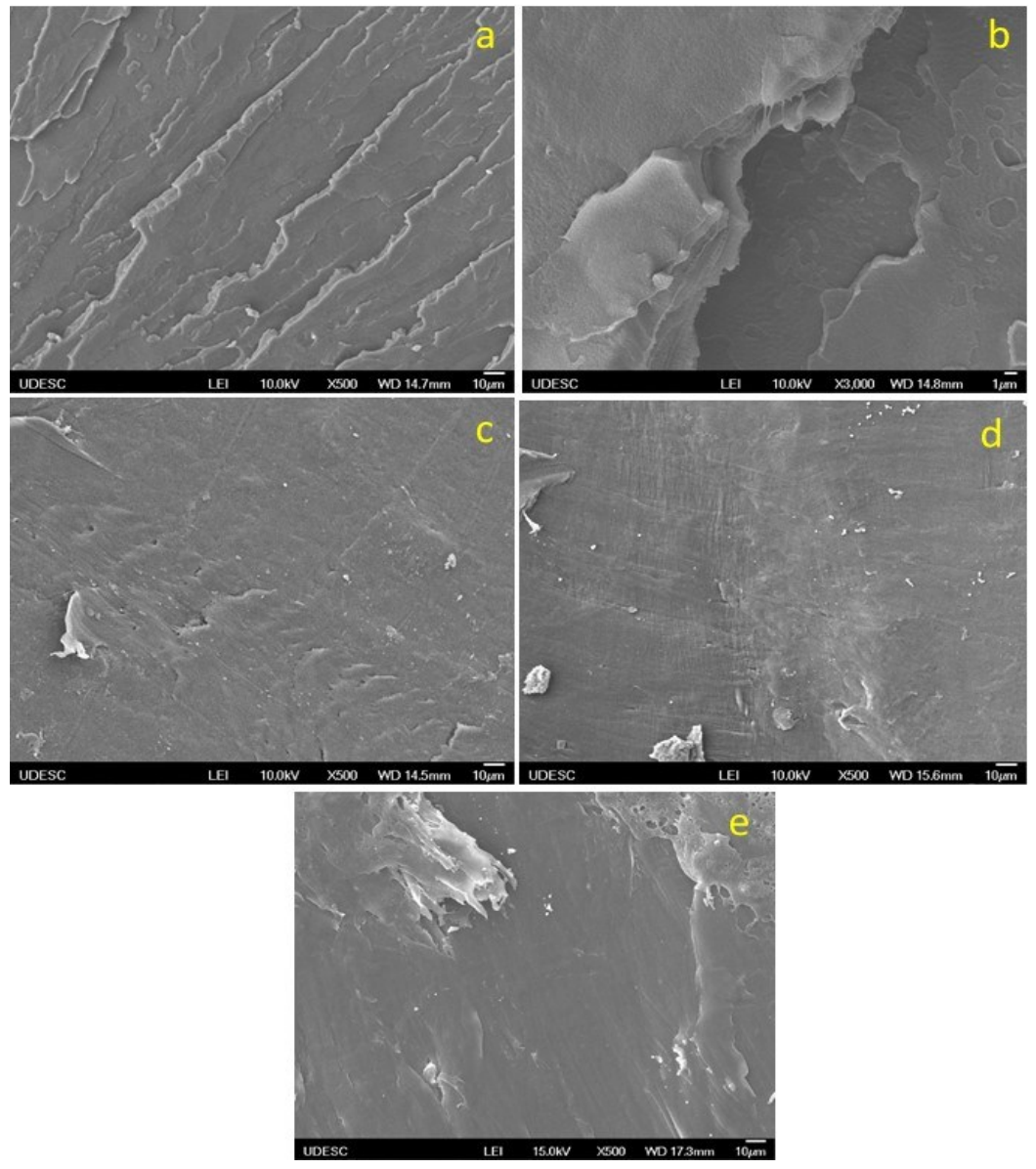

Figura 10: Micrografias de superfície de fratura obtidas por MEV-FEG para os nanocompósitos: a) branco 500x; b) branco 3.000x; c) PELBD/OMMT 2,0 500x; d) PELBD/OMMT 3,0 500x; e) PELBD/OMMT 3,5 500x.

Por meio das avaliações realizadas, é possível verificar a viabilidade da aplicação de nanoargila em polímeros, possibilitando a melhoria nas propriedades do mesmo. Em estudos similares, pode-se observar o também esses benefícios, como o aumento do módulo de elasticidade, quando aplicados em PP e PEAD, além de redução na tensão de ruptura e deformação e aumento da temperatura de cristalização do polímero com a aplicação da argila [4,5],

\section{CONCLUSÕES}

Os resultados preliminares neste trabalho demonstraram que foi possível a obtenção de nanocompósitos de PELBD com OMMT por meio do método estado fundido, e posteriormente, a obtenção de amostras injetadas do nanocompósito com a resina PELBD.

Durante as análises realizadas, percebeu-se pelas amostras injetadas com até 3,0\% de OMMT que a esfoliação ainda predomina na massa polimérica. Acima desse valor, a argila aglomera na matriz já saturada, isso foi observado também por meio da análise MEV/FEG. As análises de TGA mostraram que a adição de nanoargila elevou consideravelmente a estabilidade térmica, com destaque para a amostra PELBD/OMMT 2,0 que aumentou a estabilidade térmica em 19,9 ${ }^{\circ} \mathrm{C}$ em comparação com o Branco.

Por meio de DSC verificou-se que as amostras com incorporação de nanoargila não interferiram na temperatura de fusão do PELBD, mas o aumento percentual de nanoargila aumentou o grau de cristalinidade das amostras, com destaque para a amostra PELBD/OMMT2,5 que apresentou grau de cristalinidade $\alpha \mathrm{c}=52,7$ $\%$, que representa um aumento de $4 \%$ com relação ao branco. Os resultados de flamabilidade mostraram que a amostra PELBD/OMMT 2,0 apresentou diminuição de 37,77 \% na velocidade de propagação de chama.

No ensaio de tração percebeu-se um aumento na rigidez das amostras com adição de OMMT em comparação ao branco, aumentando o módulo de Young e diminuindo o alongamento na ruptura com o aumento percentual de OMMT. Já a técnica de RMN mostrou que as amostras de até 2,5\% de OMMT sugere a formação de um nanocompósito esfoliado. 
Com os resultados obtidos, tendo em vista a aplicação de nanocompósitos de OMMT em diferentes processos de transformação termoplásticos, indica-se a aplicação de até 3,0\% de nanoargila na massa polimérica afim de garantir alto grau de esfoliação, melhorando a estabilidade térmica do PELBD. A amostra que apresentou o melhor módulo de elasticidade foi o nanocompósito com 3,0 \%. Mas devido a análise de RMN esse valor não pode ser considerado pois com 3\% de nanoargila o nanocompósito já apresenta estrutura intercalada.

\section{BIBLIOGRAFIA}

[1] ALARIQI, S.A.S., KUMAR, A.P. "Biodegradation of g-sterilised biomedical polyolefins under composting and fungal culture environments", Polym Degrad Stab, v.91, n.5, pp.1105-1116, 2006.

[2] BONNER, J. "Nanoparticles as a Potential Cause of Pleural and Interstitial Lung Disease", Proc Am Thorac Society of Carolina do Norte, v. 7, pp. 138-141, 2010.

[3] BORSCHIVER, S., GUIMARÃES, M.J.O.C., SANTOS, T. N., et al., "Patenteamento em nanotecnologia: estudo do setor de materiais poliméricos nanoestruturados", Polímeros, v.15, n.4, pp. 245-248, 2005.

[4] BRASKEM - Polietileno de Baixa Densidade Linear. Revisão de dados 5 de maio 2010: $<$ http://www.activas.com.br/fichas/PELBD/braskem/ic32.pdf>. Acesso em 06/11/2015.

[5] MARIANO, D.M. Desenvolvimento de compósitos e/ou nanocompósitos de polietileno de alta densidade com argila organofílica via extrusão. Trabalho de conclusão de curso, Curso de Graduação de Tecnologia em Polimeros, UEZO, RJ, Brasil, 2012.

[6] PAIVA, L.B., MORALES, A.R., GUIMARÃES, T.R. "Propriedades mecânicas de nanocompósitos de polipropileno e montmorilonita organofilica", Polimeros, v.16, p. 136-140, 2006.

[7] PIRES, G. Materiais nanoestruturados do sistema epoxídico DGEBA/ dietilenotriamina modificado com um éster de silsesquioxano: propriedades mecânicas e térmicas. Dissertação de M.Sc., UNESP, São Paulo, SP, Brasil, 2006.

[8] QUENTAL, A.C., HANAMOTO, M.F. "Caracterização de Polietilenos Lineares de Baixa Densidade II e Fracionamento por Cristalização Isotérmica a Partir do Estado Fundido", Polímeros: Ciência e Tecnologia, v. 15, n.4, pp. 281-288, 2005.

[9] RAMOS, V.D., COSTA, H.M. "Propriedades mecânicas e térmicas de nanocompósitos de polietileno de alta densidade/Montmorilonita", In: IX Congresso Brasileiro de Polímeros, v. 9, 2007.

[10] ROE, A.W., CHELAZZI, L., CONNOR, C.E., et al., Toward a Unified Theory of Visual Area 4, Encyclopedia of Neuroscience, Nova Iorque, 2012.

[11] WOO, R.S.C., ZHU, H., LEUNG, C.K.Y., et al., "Environmental degradation of epoxy-organoclay nanocomposites due to UV exposure: Part II residual mechanical properties", Composites Science and Technology, v. 68, pp. 2149-2155, 2008. 